\title{
Do social interactions in the classroom improve academic attainment?
}

\section{Student sorting into classes complicates policies that utilize peer effects to optimize educational outcomes}

Keywords: education, peer effects, ability grouping, student performance, peer mechanisms

\section{ELEVATOR PITCH}

The role of social interactions in modifying individual behavior is central to many fields of social science. In education, one essential aspect is that "good" peers can potentially improve students' academic achievement, career choices, or labor market outcomes later in life. Indeed, evidence suggests that good peers are important in raising student attainment, both in compulsory schooling and university. Interventions that change the ability group composition in ways that improve student educational outcomes without exacerbating inequality therefore offer a promising basis for education policies.

\section{KEY FINDINGS}

\section{Pros}

๑ Peer effects are important for student academic achievement throughout all levels of education.

- Evidence suggests that the impact of peers is different for students of differing abilities.

( $)$ Peer effects are heterogeneous: evidence suggests that low-achieving students benefit most by being placed in a classroom with high-achieving peers.

- A higher proportion of girls in the classroom raises student attainment for both boys and girls.

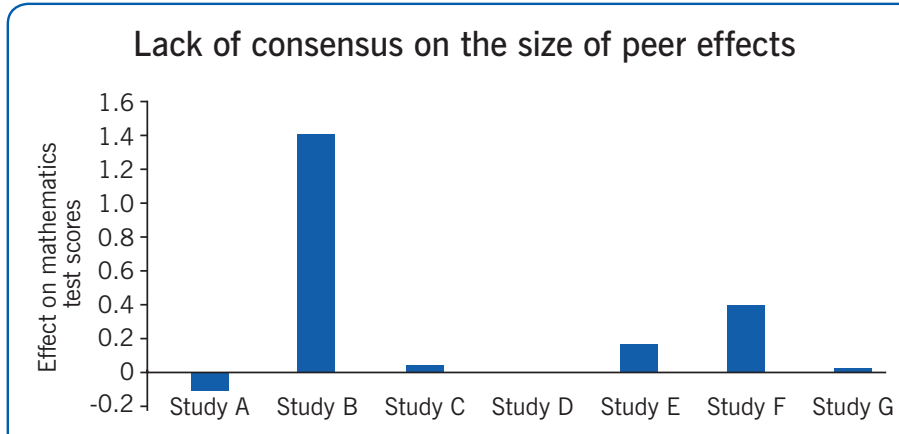

Note: Coefficients show the average impact on test scores for a selected number of studies on primary and secondary school students for a 1 point increase in their peers' quality (measured by their test score).

Source: [1].

\section{Cons}

- There is still disagreement among economists about the magnitude and shape (i.e. linear or nonlinear) of peer effects.

- It is challenging to isolate peer effects from other factors that affect student attainment, such as family background, teacher quality, or other institutional factors.

- Little is known about the mechanisms through which peer effects work.

- Given the heterogeneous nature of peer effects, it is difficult to design a single optimal policy to raise student attainment.

\section{AUTHOR'S MAIN MESSAGE}

Peer effects in education matter for students' achievement and, hence, for their success later in life. However, economists still disagree about the magnitude and shape of these effects and there is little evidence about the channels through which they might work. The contrasting nature of some research highlights a clear need for further investigation into these key areas. Nonetheless, interventions that manipulate student group composition in ways that improve the educational outcomes of low-achieving students may offer policy options that can simultaneously enhance welfare and reduce inequality. 


\section{MOTIVATION}

Education institutions are often judged according to their students' backgrounds, rather than the quality of their teaching. Many argue that social interactions among students, now generally known as "peer effects," must have an important influence on individual student achievement. The issue of peer effects is as important as ever, particularly given current educational policy in many countries, which often favors the expansion of school choice by students and their families. This freedom of choice may affect the way in which students of different prior ability are sorted across schools, which may in turn affect their overall outcomes.

Understanding the prevalence of peer effects is also important due to the potential for associated "social multiplier" effects, where educational interventions that appear beneficial when tested on an individual student may be even more effective when rolled out across the population. Motivated by these arguments, a rich economics literature has evolved in the last ten years, which attempts to understand the consequences of "peer effects." Over this period, hundreds of papers have examined empirically the importance of classroom peers on determining students' educational, social, and, more recently, labor market outcomes. A large part of this literature focusses on determining whether social interactions in the classroom matter for student academic performance, and this is also the main focus in this article.

Isolating the importance of peers from other factors affecting student attainment has proven to be a challenging task. This is because peer groups are formed endogenously, meaning individuals generally choose their own groups, so peer characteristics and unobserved individual characteristics are likely to be correlated through sorting. People sort into classrooms, schools/universities, and neighborhoods in ways that make it very difficult to disentangle self-selection effects from causal peer effects. However, it is important to identify the causal impact peers have on student academic attainment in order to provide accurate and meaningful policy recommendations. Armed with administrative data, economists have been attempting innovative ways to measure the causal effect of peers on students' academic achievement.

\section{DISCUSSION OF PROS AND CONS}

There is a strong correlation between a student's academic achievement and his or her classmates' achievement in schools or universities. However, this says little about how much of the correlation can be attributed to peer effects; how much is due to self-selection into these groups based, at least partly, on some unobserved group characteristics; and how much is due to the so called "reflection problem," which arises when student and peer achievements are determined simultaneously. There are a substantial number of studies that have attempted to disentangle peer effects from other confounding factors affecting student outcomes. To this end, economists have attempted to find contexts in which peers are exogenously assigned to one another.

\section{Evidence from cohort variation}

\section{Evidence from primary-secondary school transition}

In the absence of experimental attempts to change the mix of peers in schools, economists have tried to exploit sources of random variation in peer composition and used 
administrative data to estimate the causal impact of peers. In many countries, students move to new secondary schools after the end of their primary school years. This often forces students to re-sort themselves into new peer groups when they enter secondary school, and so experience potentially important changes in their group composition. Moreover, this remixing may vary from cohort to cohort. A study in the UK uses this remixing of students as a source of variation in peer group quality [2]. The authors isolate the effects that the new secondary school peers have on each student's own secondary school achievement. They measure peer quality as the average primary school attainment of the new secondary school peers. Taking into account sorting and selection into secondary schools, as well as controlling for unobservable pupil characteristics, schoolspecific and school-choice-specific unobserved factors that affect students who make similar school choices, the authors find that peer quality at the start of secondary school (age 11) has a significant impact on student attainment at age 14. However, these average effects are small in magnitude, and the results show no heterogeneity across student demographic types, such as gender, free meal entitlement, ethnicity, or ability groups. This finding that peer groups have little pay off in terms of the improvement in academic achievement suggests a rather limited role for peer effects in amplifying the effects of educational interventions.

\section{Evidence from school assignment based on observable prior test scores}

One reason why peer effects might vary across countries is because of differences in their educational institutional structures. In China, for example, students are assigned to secondary schools based on their entrance examination test scores. A study uses this feature to estimate peer effects in secondary schools in the Jiangsu province [3]. The authors find strong evidence of the existence of peer effects. In particular, their findings suggest that, on average, students benefit from having higher achieving schoolmates. However, unlike the UK study, the Chinese study suggests that heterogeneity in peer ability reduces attainment gains: high ability students benefit most from having higher achieving peers and from having less variation in peer quality than do students of lower ability. This suggests that there are winners and losers if students are sorted into specific schools based on their ability.

\section{Evidence from a school desegregation program}

Access to reliable measures of ability spillovers is crucial since education policies often involve the redistribution of students across schools on the basis of ability measures. One example is the Metropolitan Council for Education Opportunity (METCO) in the US, which is a desegregation program that allocates minority, mainly black and Hispanic, elementary school students to schools in more affluent, mostly white, suburbs. A key aspect of the program is that METCO students have significantly lower test scores than the receiving schools' averages. This effectively serves as an exogenous shock to peer group composition in the receiving schools, which can provide estimates of peer effects that are not contaminated by self-selection. A US study makes use of this by examining a Boston area METCO program to estimate the impact of peer effects in primary schooling [4]. The authors investigate whether increasing the proportion of minority (low-achieving) students has an impact on the academic achievement of incumbent students in the receiving schools. They find little evidence that METCO minority students affect their non-METCO classmates, concluding that there is no adverse impact of increasing the proportion of minority students in the classroom on most students. Additionally, they do not find any significant positive impacts on the minority students themselves, and 
any negative impact on those students is short-lived. This finding casts doubt on the importance of peer effects.

\section{Evidence from gender peer effects}

There is a general consensus that social interactions between gender groups play an important role in academic achievement. Thus, it is no surprise that gender peer effects have also attracted researchers' interest. A study from 2011 uses data from primary, middle, and high schools in Israel to estimate the impact of gender composition on student achievement [5]. Its findings suggest that an increase in the proportion of girls in the classroom leads to a significant improvement in the cognitive outcomes of both boys and girls. A separate study from the US also relies on random variation in the gender composition of peers to estimate peer effects in Texas elementary schools [6]. It too finds that a higher proportion of girls is associated with higher academic achievement for both boys and girls. Other studies have likewise concluded that increasing the proportion of girls in the classroom raises overall academic attainment. This broad agreement among economists suggests the potential for gender-mix interventions in improving student attainment.

\section{Evidence from experiments in higher education and the military}

Other recent studies have exploited experiments to causally estimate peer effects, thus providing more convincing evidence on their presence and magnitude. Although quite rare in the compulsory school setting, these types of studies have been more common in post-compulsory education contexts. A Dutch study uses data from a randomized experiment in a university setting to estimate peer effects originating from the ability composition of seminar/tutorial groups for economics undergraduate students [7]. The authors designed an assignment procedure to achieve a large and exogenous variation in the ability composition of the groups, thus enabling them to causally estimate the impact of peer effects on student performance. Overall, they find that students benefit from being grouped with more-able peers; in particular, there are large positive effects on the achievement of students from the lower two-thirds of the ability distribution. The dropout rate of such students is also reduced. In addition, the study finds that high ability students are unaffected by the ability composition of their group. This finding suggests that ability grouping can be beneficial, even among a homogenous group of students, as is generally the case in university settings.

Another recent experiment exploits data on first-year students at the US Air Force Academy to examine whether peers affect educational outcomes [8]. This study exploits the random assignment of students into peer groups (military squadrons) to isolate the impact of peer effects on student performance. It finds positive peer impacts on student performance and that low-achieving students benefit most from being placed in a classroom with high-achieving peers. Earlier US studies that exploited university settings to examine the relationship of roommates or dormmates, where students are assigned randomly by housing offices, have found similar results.

\section{What is known about the mechanisms through which peer effects work?}

Understanding the mechanisms through which peer effects raise educational attainment is important for policy purposes, as they provide information on how best to increase 
total learning. However, studies that have examined peer effect mechanisms are rather limited, mainly due to lack of data [1], [9]. The above-mentioned study that examined the importance of gender peer effects in Israeli schools also exploited a teacher survey to understand the mechanisms through which having a higher proportion of girls in the classroom raises student attainment [5]. The findings identify two potential channels for this effect. The first mechanism operates through changes in the classroom's gender composition, while the second operates through changes in students' behavior. The authors show that a higher proportion of girls in the classroom leads to a better learning environment, lowers the levels of disruption and violence in the classroom, and improves inter-student and student-teacher relationships [5].

Another recent study examined peer effects in a university setting in the Netherlands after randomly assigning students into classes/tutorial groups [10]. The authors find that the key mechanism through which average peer quality positively affects student grades is via changes in tutorial group interactions with their fellow students. This suggests that welfare gains by reorganizing peer groups are possible because they can lead to higher efficiency. This study also shows that adjustments in teacher behavior or student effort are not significant mechanisms.

There might be other mechanisms through which peer effects impact student academic attainment; for instance, peers might be disruptive, thereby having a negative effect. An example of this is a UK study which finds that mobile pupils (those that experience changes of school, either once or on repeated occasions) disrupt the academic achievement of immobile ones in primary schools [11]. More recent studies have linked the ability rank of students relative to the rest of their school cohort with their educational outcomes later in life. A very recent study using US data, for example, examines whether a student's ordinal rank (being the best, second-best, and so on) in his/her high school cohort affects his/her success in high school, as well as the decision to go to college. It finds that such an ordinal rank plays an important role for college choices and also success in college.

This suggests that if two students of the same ability have a different rank in their respective high school cohorts, then the one with the higher ranking is more likely to finish school and attend and complete college, while those that are ranked lower (though equally able) underinvest in human capital. Some of the potential channels, according to this study, are higher expectations about future careers, greater motivation levels, higher perceived intelligence, and more support from teachers, which in turn can lead to better future outcomes [12].

These are interesting findings as they cast light on the potential channels through which peer effects work. They provide policymakers with important information on how to tackle inefficiencies in education, by focusing on lower-ranked students, and finding ways to reduce student turnover or compensate the negative impact of these events. However, more research is needed.

\section{Policy implications of peer effects}

One of the main objectives of research on peer effects in education is to inform policymakers about how to design student assignment interventions to improve educational outcomes. Although there is a substantial number of studies that have 
attempted to causally estimate the impact of peer quality on student academic achievement, the economics literature is still inconclusive on the magnitude and shape of peer effects, and it rarely articulates the mechanisms through which peer effects work. Although there is broad agreement among economists about the existence of peer effects, results still suggest there are both strong and weak ones across a range of educational outcomes. This, in part, reflects the difficulty in defining peer groups, the challenge of isolating causal peer group effects from other influences, and a lack of appropriate data, making consistent policy implications difficult to extract.

Having access to reliable measures of ability spillovers is crucial, since many countries' education policies involve the redistribution of students across institutions on the basis of ability (e.g., charter schools and racial desegregation in the US, school academies in the UK, and ability tracking in Germany and France). Grouping students by ability can lead to higher sorting and may disadvantage low-achieving students, who often come from low-income families. This may exacerbate inequality. In this context, understanding the heterogeneous nature of peer effects becomes even more important. As discussed above, most of the literature agrees that, although important, peer quality does not affect everyone in the same way. Some studies have found that students at the bottom of the ability distribution may be affected more by higher ability peers, while high ability students may benefit more by being placed with other high ability students. Other studies have concluded differently.

The lack of consensus on the heterogeneity of peer effects, along with a lack of knowledge of the mechanisms through which they work and the complexity of social interactions within groups, make designing a single optimal policy extremely challenging. This is demonstrated in a very recent study, which designed an experiment by sorting students into classrooms with the objective of maximizing the performance of the lowest ability students [8]. However, despite its intentions, the experiment produced very different outcomes: the performance of the lowest ability students actually declined. Researchers observed that low ability students avoided high ability peers with whom they were designed to interact, and, instead, formed more homogenous subgroups. This unexpected finding demonstrates the difficulty of relying on policy interventions to manipulate peer effects to raise student academic outcomes. Therefore, a better understanding is needed about the complexities and the endogenous patterns of social interactions within groups before attempting to design welfare-enhancing education policy interventions.

\section{LIMITATIONS AND GAPS}

Although there has been a surge in the literature on peer effects in recent years, there is still disagreement on the magnitude and shape of peer effects in primary, secondary, and postsecondary education. More research is needed to identify the causal effect peer quality has on student performance, especially in primary and secondary school settings. In this respect, additional evidence based on experiments is a promising avenue for future research.

Moreover, not much is known about the channels through which peer effects work. As better data become available, and as researchers learn more about the endogenous patterns of social interactions and the mechanisms through which they work, this area will demand further study. 


\section{SUMMARY AND POLICY ADVICE}

The role of social interactions in modifying individual behavior is central to many fields of social science. If being placed in a classroom/school with high ability peers matters in determining students' academic attainment, career choice, or labor market outcomes later in life, then policymakers should favor educational interventions that affect group composition in ways that increase total learning. However, the relevant literature is inconclusive. Although there is a general consensus among economists on the importance of peers, there remains disagreement on the magnitude and shape of social interactions within educational settings. Some studies suggest that low ability students benefit from being grouped with higher ability students, while high ability students may lose out by being placed with low ability students. However, other studies reach very different conclusions.

Some of the research suggests that streaming (i.e. sorting students into schools or classrooms with homogenous ability groups) may be more beneficial, while others favor mixing students of different ability levels. However, streaming may be socially undesirable, particularly if it exacerbates inequality. In either case, more research is required into the heterogeneity of peer effects, the presence of which makes it difficult to pinpoint a single optimal policy intervention.

Although a great deal has been learnt about peer effects during the last decade, this knowledge is still not sufficient to design and implement policies that will reliably improve student outcomes. As better data become available, researchers may be better able to causally identify the effect of peers and the mechanisms through which peer effects are mediated. This would then permit the design of interventions that improve students' educational outcomes, without exacerbating inequality.

\section{Acknowledgments}

The author thanks two anonymous referees and the IZA World of Labor editors for many helpful suggestions on earlier drafts.

\section{Competing interests}

The IZA World of Labor project is committed to the IZA Guiding Principles of Research Integrity. The author declares to have observed these principles.

\section{(C) Shqiponja Telhaj}




\section{REFERENCES}

\section{Further reading}

Angrist, J. D. "The perils of peer effects." Labour Economics 30 (2014): 98-108.

Epple, D., and R. Romano. "Peer effects in education: A survey of theory and evidence." In: Benhabib, J., A. Bisin, and M. O. Jackson (eds). Handbook of Social Economics. Volume 1. Amsterdam: Elsevier B.V., 2011; pp. 1053-1163.

\section{Key references}

[1] Sacerdote, B. "Peer effects in education: How might they work, how big are they and how much do we know thus far?" In: Hanushek, E. A., S. Machin, and L. Woessmann (eds). Handbook of the Economics of Education. Volume 3. Amsterdam: Elsevier B.V., 2011; pp. 249-277.

[2] Gibbons, S., and S. Telhaj. "Peer effects: Evidence from secondary school transition in England." Oxford Bulletin of Economics and Statistics 78:4 (2016): 548-573.

[3] Ding, W., and S. Lehrer. "Do peers affect student achievement in China's secondary schools?" Review of Economics and Statistics 89:2 (2007): 300-312.

[4] Angrist, J. D., and K. Lang. "Does school integration generate peer effects? Evidence from Boston METCO program." American Economic Review 94:5 (2004): 1613-1634.

[5] Lavy, V., and A. Schlosser. "Mechanisms and impacts of gender peer effects at school." American Economic Journal: Applied Economics 3:2 (2011): 1-33.

[6] Hoxby, C. Peer Effects in the Classroom: Learning from Gender and Race Variation. NBER Working Paper No. 7867, August 2000.

[7] Booij, A. S., E. Leuven, and H. Oosterbeek. "Ability peer effects in university: Evidence from a randomized experiment." Review of Economic Studies 84:2 (2017): 547-578.

[8] Carrell, S. E., B. Sacerdote, and J. E. West. "From natural variation to optimal policy? The importance of endogenous peer group formation." Econometrica 81:3 (2013): 855-882.

[9] Sacerdote, B. "Experimental and quasi-experimental analysis of peer effects: Two steps forward?" Annual Review of Economics 6:1 (2014): 253-272.

[10] Feld, J., and U. Zölitz. "Understanding peer effects: On the nature, estimation, and channels of peer effects." Journal of Labour Economics 35:2 (2017): 387-428.

[11] Gibbons, S., and S. Telhaj. "Pupil mobility and school disruption." Journal of Public Economics 95:9-10 (2011): 1156-1167.

[12] Elsner, B., and I. Isphording. "A big fish in a small pond: Ability rank and human capital investment." Journal of Labour Economics 35:3 (2017): 787-828.

\section{Online extras}

The full reference list for this article is available from:

http://wol.iza.org/articles/do-social-interactions-in-the-classroom-improve-academic-attainment

View the evidence map for this article:

http://wol.iza.org/articles/do-social-interactions-in-the-classroom-improve-academic-attainment/map 